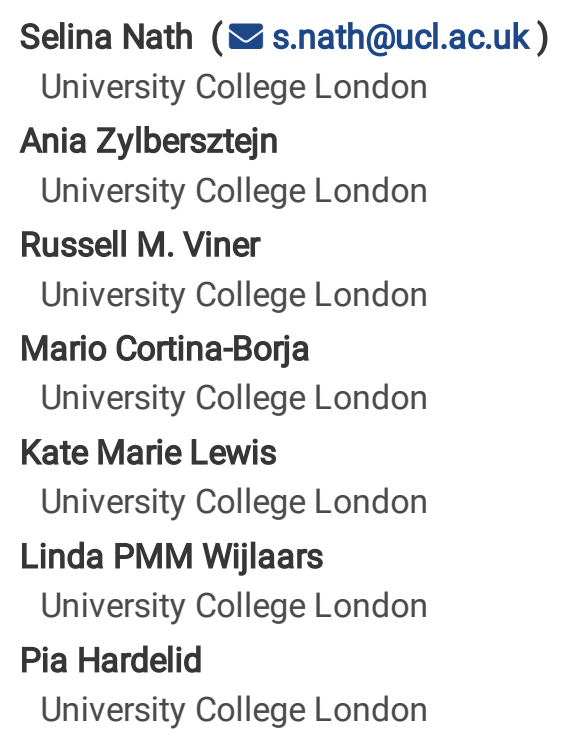

\author{
Selina Nath ( $\nabla$ s.nath@ucl.ac.uk) \\ University College London \\ Ania Zylbersztejn \\ University College London \\ Russell M. Viner \\ University College London \\ Mario Cortina-Borja \\ University College London \\ Kate Marie Lewis \\ University College London \\ Linda PMM Wijlaars \\ University College London \\ Pia Hardelid \\ University College London
}

\title{
Determinants of Accident and Emergency Attendances and Emergency Admissions in Infants: Birth Cohort Study
}

\section{Research Article}

Keywords: Emergency admissions, emergency care, infant health, local authority, variations, hospital episode statistics

Posted Date: October 6th, 2021

DOI: https://doi.org/10.21203/rs.3.rs-903488/v1

License: @ (i) This work is licensed under a Creative Commons Attribution 4.0 International License. Read Full License 


\section{Abstract}

\section{Background:}

Understanding of drivers in increasing infant accident and emergency (A\&E) attendances and emergency hospital admissions across England is limited. We examine variations in use of emergency hospital services among infants by local areas in England and investigate the extent to which infant and socio-economic factors explain these variations.

\section{Methods:}

Birth cohort study using linked administrative Hospital Episode Statistics data in England. Singleton live births between 1 April 2012 and 31 March 2019 were followed up for 1 year; from 1 April 2013 (from the discharge date of their birth admission) until their first birthday, death or 31 March 2019.

Mixed effects negative binomial models were used to calculate incidence rate ratios for A\&E attendances and emergency admissions and mixed effects logistic regression models estimated odds ratio of conversion (the proportion of infants subsequently admitted after attending A\&E). Models were adjusted individual-level factors and included a random effect for local authority (LA).

\section{Results:}

The cohort comprised 3,665,414 births in 150 English LAs. Rates of A\&E attendance and emergency admissions were highest amongst: infants born $<32$ weeks gestation; with presence of congenital anomaly; and to mothers <20-years-old. Area-level deprivation was positively associated with A\&E attendance rates, but not associated with conversion probability. A\&E attendance rates were highest in the North East (916 per 1000 child-years, 95\% Cl: 911 to 921$)$ and London (876 per 1000, 95\%Cl: 874 to 879), yet London had the lowest emergency admission rates $(232$ per $1000,95 \% \mathrm{Cl}: 231$ to 234$)$ and conversion probability (25\% vs highest $39 \%$ in South West). Adjusting for individual-level factors did not significantly affect variability in A\&E attendance and emergency admission rates by local authority.

\section{Conclusions:}

Drivers of A\&E attendances and emergency admissions include individual-level factors such being born premature, with congenital anomaly and from socio-economically disadvantaged young parent families. Support for such vulnerable infants and families should be provided alongside preventative health care in primary and community care settings. Substantial geographical variations in rates were not explained by individual-level factors, suggest more detailed understanding of local and underlying service-level factors would provide targets for further research on mechanisms and policy priority.

\section{Background}

Hospital contact rates among children peak during infancy ( $<1$ year old) (1-5), with the proportion of 'inappropriate' accident and emergency (A\&E) attendances (attendances to an emergency department that did not lead to an admission or any treatment/intervention) also being highest among infants (6). The most frequent reasons for infant admissions via A\&E departments include bronchiolitis, upper respiratory viral, intestinal infections (2), gastroenteritis jaundice and feeding difficulties (7). Over the last 15 years, England experienced substantial increases in both A\&E attendances and subsequent emergency admissions for infants; from 280 per 1000 infants in 2004 to 389 per 1000 infants in 2018 (2, 3, 7-12). Several policy changes over the years may have contributed to these increasing trends, including the 4-hour waiting targets in A\&E departments implemented between 2000-2003, changes to general practitioner (GP) contracts in 2004 leading to reduced out-of-hours services (10), and reductions in postnatal health visiting services $(13,14)$.

There are marked regional variations in rates of A\&E attendances and subsequent emergency hospital admissions for infants across England, particularly between London and elsewhere. In 2018, for example, there were 1,191 A\&E attendances per 1000 infants in London (compared to 957 per 1000 infants in England overall) (15), but 261 emergency admissions per 1000 infants in London (compared to 389 per 1000 infants in England overall) (16). Such unwarranted variations are complex and multifactorial, 
and pointing out the importance of considering individual-level maternal and infant risk factors for emergency hospital care (17, 18). Improving our understanding of the drivers of geographical variation in A\&E attendances and subsequent emergency hospital admissions for infants is, therefore, a key public health issue (19) and would enable us to determine the extent to which rates are driven by different population needs or other service related factors. As local authorities (LAs) are responsible for improving the population health, public health services and service delivery at a local level, it is important to further investigate hospital contact rates by LAs.

The NHS Long Term Plan outlines policies intended to relieve the pressure on A\&E departments by increasing both 'out-of-hours' and 'out-of-hospital' care starting from 2019/20 (20). The NHS Outcomes Framework specified reducing emergency admissions for conditions that are manageable outside of hospital as an indicator and target for health improvement (21). The Royal College of Paediatrics and Child Health (RCPCH) proposed specific strategies aimed to reduce children's A\&E attendances and emergency admissions including 'GP hotlines' enabling direct communication between primary care and paediatricians and 'Hospital at Home' services (22-24). Understanding of variations and drivers of infant hospital use would enable implementation and targeting of policies to support these strategies.

The primary aim of this study was to examine variation in use of emergency hospital services among infants in England and to explore the associated infant and socio-economic factors. The secondary aim was to examine infant and socio-economic factors associated the probability of being admitted after having attended an A\&E department (conversion probability).

\section{Methods}

\section{Data Sources}

This is a population-based birth cohort study using Hospital Episode Statistics (HES), a hospital administrative database containing data from all National Health Service (NHS) hospitals in England. HES captures data on all A\&E attendances (HES A\&E), admitted patient care (HES APC) admissions and outpatient appointments in NHS-funded hospitals across England. HES data include a unique pseudonymised patient identifier (the HESID) which enables longitudinal linkage of children's hospital contacts over time $(25,26)$. We used a previously constructed nationally representative birth cohort generated using HES APC birth episodes linked to maternal delivery episodes, which includes all singleton children born in NHS hospitals to English resident mothers. The cohort includes $97 \%$ of all births in England; full details of the birth cohort derivation are described in elsewhere (27, 28).

We extracted data on all A\&E attendances and emergency admissions for infants in the birth cohort from HES A\&E and HES APC respectively. We used the methods proposed by NHS Digital for linking A\&E attendances and emergency admissions (described in online supplementary materials S1) $(29,30)$.

\section{Study population and follow-up}

We included all children in the cohort born between 1st April 2012 and 31st March 2019. Infants were followed up from 1st April 2013 (start of follow-up) or discharge date of their birth admission (whichever occurred later), to date of first birthday, date of death, estimated date of migration or end of follow-up on 31st March 2019 (whichever came first). The study period ensured that all study years included follow-up for infants aged up to 12 months and excluded any time spent in hospital. Infants who moved out of England were identified by the presence of a non-English postcode for any A\&E attendance or emergency admission during the study period. The date of emigration was set at mid-point between the infant's start of follow-up date and the date at which the non-resident attendance or admission was recorded. Infants born $<24$ weeks gestation and multiple births were excluded. Figure 1 shows the flow-chart of data linkage and final sample of cohort infants used in the analysis.

\section{Outcomes}

The study's primary outcomes were rates of A\&E attendances and rates of emergency admissions in infants. The secondary outcome was conversion the probability, i.e. the proportion of children admitted to hospital after attending A\&E.

Page 3/19 
A\&E attendances were identified using the HES A\&E dataset and defined as an unplanned attendance to a 24-hour consultant-led A\&E department, consultant-led mono specialty A\&E department (e.g. ophthalmology or dental A\&E departments), and other types of A\&E departments and minor injury units. Follow-up A\&E attendances, attendances at NHS walk-in centres, and A\&E attendances in private hospitals were excluded. For infants with more than one A\&E attendance in one day, only the last attendance was included to avoid double counting and allow linkage with a potential subsequent emergency admission.

\section{Emergency admissions}

The HES APC dataset was used to identify emergency admissions. We identified two distinct pathways to an emergency admission within the APC dataset using the variable 'admission method'. The first was via a hospital A\&E attendance (indirect), where parents/carers would take infants to an A\&E department in a hospital and the infant was then admitted as an emergency from the A\&E department (also called conversion). The second was a direct hospital admission (circumventing an A\&E attendance, often made by a general practitioner; GP). We included all emergency admissions (irrespective of admission pathway) for analysis. Admissions were classified as an emergency if the first episode of care within a multi-episode admission was recorded as an emergency episode.

\section{Infant And Maternal Risk Factors}

Infant birth characteristics included infant's sex, gestational age at birth defined as severe prematurity ( $<32$ weeks), moderate prematurity (32-33 weeks), near term (34-36 weeks), and term ( $\geq 37$ weeks) (31), and congenital anomalies, identified using an International Classification of Diseases version 10 (ICD10) code list $(28,32)$. Children were classified as having a congenital anomaly if a relevant code was recorded at birth, during any hospital admission before 2 years of age, or on a death certificate as any cause of death. Maternal age was categorised as under 20, 20-29, 30-39 and 40+ years at the time of delivery (33). Quintiles of the Index of Multiple Deprivation score (IMD, 2010 version) were used as an indicator of socio-economic status. The IMD is a composite measure of multiple deprivation at Lower Super Output Area level (covering 1500 people on average) across seven domains $(34,35)$. HES financial years (running April to March in the UK) were used to ensure comparison of annual rates published by Public Health England (PHE) $(15,16,36)$.

We used information about infant's local authority (LA) of residence at birth to examine variations in A\&E attendances and emergency admissions across English local areas. There were 152 LAs (upper tier) across England during the study period. Due to small population sizes (< 1000 births across the study period), we combined the City of London with Hackney, and the Isles of Scilly with Cornwall. This resulted in 150 LAs included in the analyses. LAs were grouped into region of residence (North East, North West, Yorkshire and Humber, East Midlands, West Midlands, East of England, London, South East, and South West) to describe overall patterns of A\&E attendances and emergency admissions at a regional level in England.

\section{Statistical Methods}

We described distribution of region, infant and maternal risk factors for children in the cohort (overall and in complete case cohort excluding children with missing data). Main analyses were restricted to complete case cohort. Rates of A\&E attendances and emergency admissions were calculated per 1000 child-years, overall and stratified according to all risk factors (37).

We fitted mixed-effects negative binomial regression models to examine the association between infant and maternal risk factors and rates of A\&E attendances and admissions and derive incidence rate ratios (IRRs) (38). The outcome variable was counts of A\&E attendances or emergency admissions; separate models were fitted for each outcome. Year and month of birth (categorised as standard calendar quarters), infant's sex and gestational age, presence of congenital anomaly, maternal age, and quintiles of IMD were included as exposure variables, and person-time at risk as the offset. Risk factors to be included in the models were selected a priori. Year and month of birth were included in the first model (model 1), then infant-related variables (infant sex, gestational age, presence of congenital anomaly) were added (model 2), and finally, maternal age, and quintiles of IMD were 
included (model 3). Heterogeneity due to unobserved variables within LAs was accounted for with a random effect term in the intercept of the models. Variance Partition Coefficients (VPC) defined as: $\frac{\sigma_{u}^{2}}{\sigma_{u}^{2}+\sigma_{e}^{2}}$ (Eq. 1),

that is, as the ratio of the residual variance due to between-LA random effects $\left(\sigma_{u}^{2}\right)$ and the total residual variance. Thus, VPC can be interpreted as the proportion of the total residual variance attributable to the random effects $(38,39)$. In other words, the proportion of variation that is beyond that explained by the fixed predictors that is due to between-LA variation.

We assessed goodness-of-fit for all models by changes in Bayesian information criterion (BIC) (40), with smaller values indicating better model fit. Normal probability plots of deviance residuals were used to determine deviations outside of the normal expected range, as only $5 \%$ of deviance residuals should lie outside \pm 1.96 . The assumption of normality for the models' random effects was assessed with probability plots of the individual random effects predictions.

To visually examine LA level variation in rates of A\&E attendances and emergency admissions, we used crude and adjusted rates to construct funnel plots with multiplicative over-dispersion adjusted control limits. Expected events were obtained from the final model's predictions using both the fixed effects estimates and the LA random effect term (model 3). Adjusted rates were then calculated as the observed number of events divided by the expected number of events obtained using predictions from the final model for each outcome, multiplied by the overall crude rate for England (41). To further explore the contribution of infant and maternal factors within the model, we compared LA effect predictions from the final adjusted mixed-effects models (model 3 ) against those from model 1 (i.e., the null model). Maps were generated to show variations of adjusted rates (per 1000 child-years) of A\&E attendances, emergency admissions and conversation probabilities by local authorities across England.

\section{Models for conversion probabilities}

Mixed-effects logistic regression models were fitted to determine the association between individual-level infant and maternal characteristics, and the probability of being admitted to hospital given that the infant had attended A\&E (the conversion probability). These models were parametrised in terms of odds ratios. We included the same covariates and used the same model selection strategy as for the negative binomial regression models described above. LA was included as a random effect in the models' intercept. For this analysis, we selected at random one A\&E attendance per infant for those with multiple A\&E attendances during infancy. VPC was calculated using:

$\frac{\sigma_{u}^{2}}{\sigma_{u}^{2}+\frac{\pi^{2}}{3}}$ (Eq. 2),

where $\sigma_{u}^{2}$ is the variance of the within LA random effects (level 2), and the level 1 variance for a logistic regression model is obtained as the variance of the standard logistic distribution, $\frac{\pi^{2}}{3}(42)$.

\section{Sensitivity analyses}

Logistic regression models were used to examine factors that were associated with missingness (outcome: complete data vs any missing data) showing that gestational age was associated with increased odds of missing information. To investigate the potential influence of missing data on the results, we ran all final models including an additional category of missing to the infant gestational age category. All statistical analysis were conducted in STATA v16 (43).

\section{Results}

\section{Study Population}

The distribution of infant, maternal and geographical variables with complete $(n=3,672,700)$ and missing data $(n=612,643)$ are shown in online supplementary table S2. Infant's gestation at birth had the most missing data $(12.5 \%$ missing data vs $<3 \%$ for other variables) and were more common for preterm born (<37 weeks) infants (OR 2.03, 95\% Cl 1.92-2.16). Figure 1 shows flowchart of the final study cohort. Of all singleton births in our complete dataset, $0.19 \%(n=7,286)$ had follow-up $<1$ day follow-up and were excluded from further analyses. The final study cohort population included 3,665,414 singleton infants from 150 LAs, 
with mean follow-up time per infant of 342 days (median $=365$ days). There were 2,241,892 A\&E attendances and 1,051,619 emergency admissions during the study period; 716,838 (68\%) emergency admissions were via A\&E and 334,781 (32\%) were admissions directly to a ward. Of the direct admissions, 307,498 (92\%) were from GPs.

Table 1 shows the distribution of characteristics in the study cohort included in the analysis. The overall A\&E attendance rate was 720 per 1000 child-years $(95 \% \mathrm{Cl}: 719-721)$ and the emergency hospital admission rate 338 per 1000 child-years (95\%Cl: 337338). The annual rates by financial years broadly followed published rates (see Table 1) $(15,16)$. We identified substantial regional variations in A\&E attendance and hospital admission rates. A\&E attendance rates were highest in the North East (916 per 1000 child-years, 95\%Cl: 911-921) and London (876 per 1000 child-years, 95\% Cl: 874-879), yet London had the lowest emergency admission rates (232 per 1000 child-years, 95\% Cl: 231-234) and lowest conversion proportion (25\%) (see Fig. 2). Infants who were male, born at < 32 weeks' gestation or with congenital anomalies, from the most deprived SES quintile or with young mothers had higher A\&E attendance and admission rates.

Table 1: Cohort sociodemographic and rates $(95 \% \mathrm{Cl})$ of $A \& E$ attendance and emergency admissions 


\begin{tabular}{|c|c|c|c|c|c|c|}
\hline & \multicolumn{2}{|l|}{ All infants } & \multicolumn{2}{|c|}{ A\&E attendances of infants } & \multicolumn{2}{|c|}{ Emergency admissions of infants } \\
\hline & $\mathrm{N}$ & $\%$ & Count (\%) & $\begin{array}{l}\text { Rate per } 1000 \text { infant- } \\
\text { years }(95 \% \mathrm{Cl})\end{array}$ & Count (\%) & $\begin{array}{l}\text { Rate per } 1000 \text { infant- } \\
\text { years }(95 \% \mathrm{Cl})\end{array}$ \\
\hline Total & $3,665,414$ & 100 & $\begin{array}{l}2,241,892 \\
(100)\end{array}$ & 720.1 (719.2 to 721.1$)$ & $\begin{array}{l}1,051,619 \\
(100)\end{array}$ & 337.8 (337.1 to 338.4$)$ \\
\hline Year & \multicolumn{2}{|l|}{ Year of birth } & \multicolumn{2}{|c|}{ Year of A\&E attendance ${ }^{a}$} & \multicolumn{2}{|c|}{ Year of emergency admission ${ }^{b}$} \\
\hline 2012/13 & 561,558 & 15 & & & & \\
\hline 2013/14 & 532,303 & 15 & $\begin{array}{l}343,220 \\
(15.3)\end{array}$ & 634.1 (632 to 636.2$)$ & $\begin{array}{l}168,690 \\
(16.0)\end{array}$ & 311.7 (310.2 to 313.2$)$ \\
\hline $2014 / 15$ & 523,287 & 14 & $\begin{array}{l}333,812 \\
(14.9)\end{array}$ & $639.4(637.2$ to 641.6$)$ & $\begin{array}{l}166,616 \\
(15.8)\end{array}$ & 319.1 (317.6 to 320.7$)$ \\
\hline 2015/16 & 526,828 & 14 & $\begin{array}{l}367,478 \\
(16.4)\end{array}$ & 706.6 (704.3 to 708.9$)$ & $\begin{array}{l}174,781 \\
(16.6)\end{array}$ & 336.1 (334.5 to 337.6$)$ \\
\hline 2016/17 & 517,687 & 14 & $\begin{array}{l}394,000 \\
(17.6)\end{array}$ & 762.0 (759.6 to 764.4$)$ & $\begin{array}{l}182,495 \\
(17.4)\end{array}$ & 352.9 (351.3 to 354.6$)$ \\
\hline 2017/18 & 522,047 & 14 & $\begin{array}{l}395,102 \\
(17.6)\end{array}$ & 768.0 (765.6 to 770.4$)$ & $\begin{array}{l}176,731 \\
(16.8)\end{array}$ & 343.5 (341.9 to 345.1$)$ \\
\hline 2018/19 & 481,704 & 13 & $\begin{array}{l}408,280 \\
(18.2)\end{array}$ & 819.3 (816.8 to 821.8$)$ & $\begin{array}{l}182,306 \\
(17.3)\end{array}$ & 365.8 (364.2 to 367.5$)$ \\
\hline \multicolumn{7}{|c|}{ Month of birth } \\
\hline January & 301,035 & 8 & $\begin{array}{l}183,634 \\
(8.2)\end{array}$ & 713.5 (710.3 to 716.8$)$ & $\begin{array}{l}84,619 \\
(8.0)\end{array}$ & 328.8 (326.6 to 331 ) \\
\hline February & 270,279 & 7 & $\begin{array}{l}164,126 \\
(7.3)\end{array}$ & 707.3 (703.9 to 710.7 ) & $\begin{array}{l}75,879 \\
(7.2)\end{array}$ & 327.0 (324.7 to 329.3$)$ \\
\hline March & 286,214 & 8 & $\begin{array}{l}174,659 \\
(7.8)\end{array}$ & 704.4 (701.1 to 707.7) & $\begin{array}{l}81,002 \\
(7.7)\end{array}$ & 326.7 (324.4 to 328.9 ) \\
\hline April & 299,542 & 8 & $\begin{array}{l}180,024 \\
(8.0)\end{array}$ & 715.5 (712.2 to 718.8$)$ & $\begin{array}{l}83,205 \\
(7.9)\end{array}$ & 330.7 (328.4 to 332.9$)$ \\
\hline May & 316,786 & 9 & $\begin{array}{l}191,011 \\
(8.5)\end{array}$ & 718.6 (715.4 to 721.9$)$ & $\begin{array}{l}88,419 \\
(8.4)\end{array}$ & 332.7 (330.5 to 334.9 ) \\
\hline June & 308,684 & 8 & $\begin{array}{l}188,949 \\
(8.4)\end{array}$ & 725.7 (722.4 to 729$)$ & $\begin{array}{l}87,813 \\
(8.4)\end{array}$ & 337.3 (335 to 339.5 ) \\
\hline July & 323,267 & 9 & $\begin{array}{l}198,965 \\
(8.9)\end{array}$ & 726.8 (723.6 to 730$)$ & $\begin{array}{l}93,189 \\
(8.9)\end{array}$ & 340.4 (338.2 to 342.6$)$ \\
\hline August & 318,448 & 9 & $\begin{array}{l}195,863 \\
(8.7)\end{array}$ & 727.5 (724.3 to 730.7$)$ & $\begin{array}{l}91,883 \\
(8.7)\end{array}$ & 341.3 (339.1 to 343.5$)$ \\
\hline
\end{tabular}

a Public Health England fingertips reported rates for annual A\&E attendances in infants < 1 years old were 688.3 (2013/14), $719.6(2014 / 15), 798.6(2015 / 16), 859.9$ (2016/17), $885.1(2017 / 18)$ and $957.4(2018 / 19)$ per 1000 population (15). Although our rates were lower potentially due to additional data cleaning, linkage to birth cohort of singleton infants born in the UK and exclusion of those with missing data, the pattern of rates by year were comparable.

b Public Health England fingertips reported rates for annual emergency admissions in infants $<1$ years old were 326.3 (2013/14), 338.1 (2014/15), 357.7 (2015/16), 369.0 (2016/17), $365.3(2017 / 18)$ and $388.6(2018 / 19)$ per 1000 population (16). Although our rates were lower potentially due to additional data cleaning, linkage to birth cohort of singleton infants born in the UK and exclusion of those with missing data, the pattern of rates by year were comparable.

${ }^{\mathrm{c}}$ NHS Digital Hospital Episode Statistics (HES) disclosure states all HES sub-national data is subject to suppression and rounded to the nearest 5. Therefore, counts for IMD Quintile and Region were rounded accordingly (30). 


\begin{tabular}{|c|c|c|c|c|c|c|}
\hline \multirow[b]{2}{*}{ September } & \multicolumn{2}{|l|}{ All infants } & \multicolumn{2}{|c|}{ A\&E attendances of infants } & \multicolumn{2}{|c|}{ Emergency admissions of infants } \\
\hline & 321,338 & 9 & $\begin{array}{l}197,154 \\
(8.8)\end{array}$ & 723.6 (720.4 to 726.8$)$ & $\begin{array}{l}95,187 \\
(9.1)\end{array}$ & $349.4(347.1$ to 351.6$)$ \\
\hline October & 319,677 & 9 & $\begin{array}{l}197,791 \\
(8.8)\end{array}$ & 728.5 (725.3 to 731.7$)$ & $\begin{array}{l}97,303 \\
(9.3)\end{array}$ & $358.4(356.1$ to 360.6$)$ \\
\hline November & 301,002 & 8 & $\begin{array}{l}186,145 \\
(8.3)\end{array}$ & 727.1 (723.8 to 730.4$)$ & $\begin{array}{l}88,768 \\
(8.4)\end{array}$ & 346.7 (344.5 to 349$)$ \\
\hline December & 299,142 & 8 & $\begin{array}{l}183,571 \\
(8.2)\end{array}$ & 719.5 (716.2 to 722.8$)$ & $\begin{array}{l}84,352 \\
(8.0)\end{array}$ & 330.6 (328.4 to 332.9$)$ \\
\hline \multicolumn{7}{|l|}{ Sex } \\
\hline Male & $1,881,844$ & 51 & $\begin{array}{l}1,250,909 \\
(55.8)\end{array}$ & 783.2 (781.8 to 784.6$)$ & $\begin{array}{l}601,658 \\
(57.2)\end{array}$ & 376.7 (375.8 to 377.7 ) \\
\hline Female & $1,783,570$ & 49 & $\begin{array}{l}990,983 \\
(44.2)\end{array}$ & 653.6 (652.4 to 654.9$)$ & $\begin{array}{l}449,961 \\
(42.8)\end{array}$ & 296.8 (295.9 to 297.7$)$ \\
\hline \multicolumn{7}{|l|}{ Gestation at birth } \\
\hline $37+$ Term & $3,457,537$ & 94 & $\begin{array}{l}2,039,640 \\
(91.0)\end{array}$ & 693.2 (692.3 to 694.2) & $\begin{array}{l}929,728 \\
(88.4)\end{array}$ & 316.0 (315.4 to 316.6$)$ \\
\hline 34-36:Near Term & 26,286 & 1 & $\begin{array}{l}36,590 \\
(1.6)\end{array}$ & $\begin{array}{l}1926.3 \text { (1906.6 to } \\
\text { 1946.1) }\end{array}$ & $\begin{array}{l}25,803 \\
(2.5)\end{array}$ & $\begin{array}{l}1358.4(1341.9 \text { to } \\
1375.1)\end{array}$ \\
\hline $\begin{array}{l}\text { 32-33:Moderate } \\
\text { prematurity }\end{array}$ & 23,959 & 1 & $\begin{array}{l}23,818 \\
(1.1)\end{array}$ & $\begin{array}{l}1228.2 \text { (1212.7 to } \\
1243.9)\end{array}$ & $\begin{array}{l}14,902 \\
(1.4)\end{array}$ & 768.4 (756.2 to 780.9$)$ \\
\hline $\begin{array}{l}<31 \text { :Severe \&extreme } \\
\text { prematurity }\end{array}$ & 157,632 & 4 & $\begin{array}{l}141,844 \\
(6.3)\end{array}$ & $\begin{array}{l}1068.6 \text { (1063.1 to } \\
\text { 1074.2) }\end{array}$ & $\begin{array}{l}81,186 \\
(7.7)\end{array}$ & $611.6(607.4$ to 615.9$)$ \\
\hline \multicolumn{7}{|l|}{ Congenital anomaly } \\
\hline No & $3,550,426$ & 97 & $\begin{array}{l}2,076,303 \\
(92.6)\end{array}$ & 687.6 (686.7 to 688.6$)$ & $\begin{array}{l}933,323 \\
(88.8)\end{array}$ & 309.1 (308.5 to 309.7$)$ \\
\hline Yes & 114,988 & 3 & $\begin{array}{l}165,589 \\
(7.4)\end{array}$ & 1766.5 (1758 to 1775$)$ & $\begin{array}{l}118,296 \\
(11.2)\end{array}$ & $\begin{array}{l}1262.0 \text { (1254.8 to } \\
1269.2)\end{array}$ \\
\hline \multicolumn{7}{|l|}{ IMD Quintile ${ }^{c}$} \\
\hline Q1: Most deprived & $1,017,935$ & 28 & $\begin{array}{l}758,620 \\
(33.8)\end{array}$ & 878.8 (876.8 to 880.8 ) & $\begin{array}{l}320,180 \\
(30.4)\end{array}$ & 370.9 (369.6 to 372.2$)$ \\
\hline Q2 & 817,545 & 22 & $\begin{array}{l}521,845 \\
(23.3)\end{array}$ & 752.0 (750 to 754$)$ & $\begin{array}{l}234,770 \\
(22.3)\end{array}$ & 338.3 (337 to 339.7 ) \\
\hline Q3 & 682,265 & 19 & $\begin{array}{l}382,020 \\
(17.0)\end{array}$ & 658.6 (656.5 to 660.7$)$ & $\begin{array}{l}189,805 \\
(18.0)\end{array}$ & 327.2 (325.8 to 328.7 ) \\
\hline Q4 & 592,180 & 16 & $\begin{array}{l}309,765 \\
(13.8)\end{array}$ & 615.3 (613.1 to 617.4$)$ & $\begin{array}{l}162,995 \\
(15.5)\end{array}$ & 323.7 (322.2 to 325.3) \\
\hline \multicolumn{7}{|c|}{$\begin{array}{l}\text { a Public Health England fingertips reported rates for annual A\&E attendances in infants }<1 \text { years old were } 688.3(2013 / 14) \text {, } \\
719.6(2014 / 15), 798.6(2015 / 16), 859.9(2016 / 17), 885.1(2017 / 18) \text { and } 957.4(2018 / 19) \text { per } 1000 \text { population }(15) \text {. } \\
\text { Although our rates were lower potentially due to additional data cleaning, linkage to birth cohort of singleton infants born in } \\
\text { the UK and exclusion of those with missing data, the pattern of rates by year were comparable. }\end{array}$} \\
\hline \multicolumn{7}{|c|}{$\begin{array}{l}\text { b Public Health England fingertips reported rates for annual emergency admissions in infants }<1 \text { years old were } 326.3 \\
(2013 / 14), 338.1(2014 / 15), 357.7(2015 / 16), 369.0(2016 / 17), 365.3(2017 / 18) \text { and } 388.6(2018 / 19) \text { per } 1000 \text { population } \\
\text { (16). Although our rates were lower potentially due to additional data cleaning, linkage to birth cohort of singleton infants born } \\
\text { in the UK and exclusion of those with missing data, the pattern of rates by year were comparable. }\end{array}$} \\
\hline NHS Digital Hospital & tatistic & & losure st & all HES sub-national & $\begin{array}{l}\text { is sub } \\
\text { dingly }\end{array}$ & suppression and \\
\hline
\end{tabular}




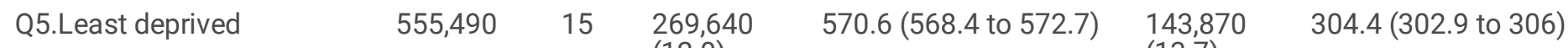
$(12.0)$

(13.7)

\section{Region ${ }^{\mathrm{c}}$}

\begin{tabular}{|c|c|c|c|c|c|c|}
\hline North East & 169,965 & 5 & $\begin{array}{l}132,465 \\
(5.9)\end{array}$ & 916.0 (911.1 to 920.9) & $\begin{array}{l}63,135 \\
(6.0)\end{array}$ & $436.6(433.2$ to 440$)$ \\
\hline North West & 496,105 & 14 & $\begin{array}{l}356,515 \\
(15.9)\end{array}$ & 847.7 (844.9 to 850.5$)$ & $\begin{array}{l}197,670 \\
(18.8)\end{array}$ & 470.0 (467.9 to 472.1$)$ \\
\hline Yorkshire and Humber & 363,085 & 10 & $\begin{array}{l}223,945 \\
(10.0)\end{array}$ & 732.3 (729.2 to 735.3 ) & $\begin{array}{l}104,740 \\
(10.0)\end{array}$ & 342.5 (340.4 to 344.6$)$ \\
\hline East Midlands & 298,845 & 8 & $\begin{array}{l}156,680 \\
(7.0)\end{array}$ & $624.3(621.2$ to 627.4$)$ & $\begin{array}{l}77,740 \\
(7.4)\end{array}$ & 309.8 (307.6 to 312 ) \\
\hline West Midlands & 406,340 & 11 & $\begin{array}{l}239,290 \\
(10.7)\end{array}$ & 691.5 (688.7 to 694.3$)$ & $\begin{array}{l}130,660 \\
(12.4)\end{array}$ & 377.6 (375.5 to 379.6$)$ \\
\hline East of England & 376,090 & 10 & $\begin{array}{l}197,060 \\
(8.8)\end{array}$ & 619.5 (616.8 to 622.3$)$ & $\begin{array}{l}101,150 \\
(9.6)\end{array}$ & 318.0 (316.1 to 320$)$ \\
\hline London & 655,480 & 18 & $\begin{array}{l}485,830 \\
(21.7)\end{array}$ & 876.2 (873.8 to 878.7$)$ & $\begin{array}{l}128,735 \\
(12.2)\end{array}$ & 232.2 (230.9 to 233.5$)$ \\
\hline South East & 554,670 & 15 & $\begin{array}{l}301,160 \\
(13.4)\end{array}$ & $630.4(628.2$ to 632.7$)$ & $\begin{array}{l}146,355 \\
(13.9)\end{array}$ & 306.4 (304.8 to 308$)$ \\
\hline South West & 344,830 & 9 & $\begin{array}{l}148,940 \\
(6.6)\end{array}$ & $504.9(502.3$ to 507.4$)$ & $\begin{array}{l}101,430 \\
(9.6)\end{array}$ & 343.8 (341.7 to 345.9$)$ \\
\hline \multicolumn{7}{|l|}{ Maternal Age } \\
\hline Under 20 & 133,057 & 4 & $\begin{array}{l}126,233 \\
(5.6)\end{array}$ & $\begin{array}{l}1133.1 \text { (1126.8 to } \\
1139.3)\end{array}$ & $\begin{array}{l}53,553 \\
(5.1)\end{array}$ & 480.7 (476.6 to 484.8$)$ \\
\hline $20-29$ & $1,627,985$ & 44 & $\begin{array}{l}1,113,349 \\
(49.7)\end{array}$ & 805.4 (803.9 to 806.9$)$ & $\begin{array}{l}520,738 \\
(49.5)\end{array}$ & 376.7 (375.7 to 377.7$)$ \\
\hline
\end{tabular}

a Public Health England fingertips reported rates for annual A\&E attendances in infants $<1$ years old were 688.3 (2013/14), 719.6 (2014/15), 798.6 (2015/16), 859.9 (2016/17), 885.1 (2017/18) and $957.4(2018 / 19)$ per 1000 population (15). Although our rates were lower potentially due to additional data cleaning, linkage to birth cohort of singleton infants born in the UK and exclusion of those with missing data, the pattern of rates by year were comparable.

b Public Health England fingertips reported rates for annual emergency admissions in infants $<1$ years old were 326.3 (2013/14), 338.1 (2014/15), 357.7 (2015/16), 369.0 (2016/17), $365.3(2017 / 18)$ and $388.6(2018 / 19)$ per 1000 population (16). Although our rates were lower potentially due to additional data cleaning, linkage to birth cohort of singleton infants born in the UK and exclusion of those with missing data, the pattern of rates by year were comparable.

${ }^{\mathrm{c}}$ NHS Digital Hospital Episode Statistics (HES) disclosure states all HES sub-national data is subject to suppression and rounded to the nearest 5. Therefore, counts for IMD Quintile and Region were rounded accordingly (30). 


\begin{tabular}{|lllllll|}
\hline & All infants & \multicolumn{3}{c|}{ A\&E attendances of infants } & \multicolumn{2}{l|}{ Emergency admissions of infants } \\
\hline $30-39$ & $1,759,622$ & 48 & $\begin{array}{l}927,821 \\
(41.4)\end{array}$ & $619.9(618.6$ to 621.2) & $\begin{array}{l}442,373 \\
(42.1)\end{array}$ & 295.6 (294.7 to 296.4) \\
\hline $40+$ & 144,750 & 4 & $\begin{array}{l}74,489 \\
(3.3)\end{array}$ & $606.5(602.2$ to 610.9) & $\begin{array}{l}34,955 \\
(3.3)\end{array}$ & 284.6 (281.7 to 287.6) \\
\hline
\end{tabular}

a Public Health England fingertips reported rates for annual A\&E attendances in infants < 1 years old were 688.3 (2013/14), 719.6 (2014/15), 798.6 (2015/16), 859.9 (2016/17), 885.1 (2017/18) and 957.4 (2018/19) per 1000 population (15). Although our rates were lower potentially due to additional data cleaning, linkage to birth cohort of singleton infants born in the UK and exclusion of those with missing data, the pattern of rates by year were comparable.

b Public Health England fingertips reported rates for annual emergency admissions in infants $<1$ years old were 326.3 (2013/14), 338.1 (2014/15), 357.7 (2015/16), 369.0 (2016/17), $365.3(2017 / 18)$ and $388.6(2018 / 19)$ per 1000 population (16). Although our rates were lower potentially due to additional data cleaning, linkage to birth cohort of singleton infants born in the UK and exclusion of those with missing data, the pattern of rates by year were comparable.

${ }^{c}$ NHS Digital Hospital Episode Statistics (HES) disclosure states all HES sub-national data is subject to suppression and rounded to the nearest 5 . Therefore, counts for IMD Quintile and Region were rounded accordingly (30).

\section{A\&E attendances}

A\&E attendance rates were more than twice as high for infants who were born with congenital anomalies (IRR: $2.30,95 \% \mathrm{Cl}$ : 2.282.32; Fig. 3) or at < 32 weeks (IRR: $1.94,95 \% \mathrm{Cl}$ : 1.92 to 1.96) compared to those without congenital anomalies or born at full-term. Infants born to mothers delivering aged $\geq 40$ years had lower rates of A\&E attendances (IRR: 0.94, 95\%Cl: 0.93-0.95) and infants born to mothers aged under 20-years-old had $82 \%$ higher attendance rate than infants whose mothers were aged between 30 to 39 years (IRR: $1.82,95 \% \mathrm{Cl}: 1.81-1.84$ ). Infants from the most deprived SES quintile had $14 \%$ higher rates compared to those from the least deprived (IRR: 1.14, 95\% Cl: 1.13-1.15). Model 3 provided the best fit to A\&E attendance rates (for full model outputs and model fit statistics see online supplementary materials table S3 and figure S7A).

We identified substantial variation in adjusted A\&E attendances rates by LA across England (Fig. 4A). Funnel plots of crude and adjusted $A \& E$ attendance rates in England showed that allowing for individual-level factors did not significantly change variations by LA (Fig. 5A). 17 (11\%) LAs whose unadjusted crude rates fell outside the $95 \%$ control limits (vs $5 \%$ expected outside of the $95 \%$ control limits), similar to the $15(10 \%)$ adjusted rates from LAs outside these limits. The VPC for adjusted model was 0.12 .

Comparing predicted LA effect values from the final adjusted mixed effect models and the null model, showed a high correlation (online supplementary Figure S8A), confirming that individual-level factors explained little of the overall variations in A\&E attendance rates (online supplementary Figure S9A for Normal probability plots of random effects predictions).

\section{Emergency admissions}

Emergency admissions were more than three times higher in infants with congenital anomalies (IRR: $3.42,95 \%$ Cl: 3.39 to 3.45 ) and twice as high in infants born severely premature (IRR: $2.46,95 \% \mathrm{Cl}: 2.42$ to 2.50 ), compared to those born without congenital anomalies or full-term (Fig. 3). Emergency admission rates were $45 \%$ higher for infants whose mothers were $<20$ years old, compared to infants whose mothers were $30-39$ years-old (IRR: $1.45,95 \% \mathrm{Cl}: 1.44$ to 1.47 ). Model 3 had the best values of all goodness-of-fit statistics (for full model outputs and model fit statistics see online supplementary materials table S4 and figure S7B).

Allowing for individual-level factors did not substantially reduce the substantial variation by LA (Fig. 4B, Fig. 5B). For the unadjusted crude rates only 6 (4\%) LAs fell outside the $95 \%$ control limits, and $4(3 \%)$ rates from the adjusted model, similar to the expected $5 \%$ normal variation outside of the $95 \%$ control limits. The VPC of the fully adjusted model was 0.12 .

Predicted LA effect values from final adjusted mixed effect models and the null model, showed a high correlation (online supplementary Figure S8B). See online supplementary Figure S9B for normal probability plots of random effects predictions.

\section{Conversion probabilities}

Page $10 / 19$ 
Of all infants in the cohort that had an A\&E attendance during the study period, the overall conversion probability was $32 \%$ $(716,838 / 2,241,892)$ and but was substantial variation across LAs in England (Fig. 4C). Compared to infants born in financial year 2012/13, infants born in subsequent financial years had increased odds of being admitted via A\&E 2018/19 OR: 2.09, 95\%Cl: 2.05 to 2.13) (see Fig. 3, online supplementary table S5 for all models and goodness-of-fit statistics, figure S10 and S11). ORs showed similar direction of trends as IRR for emergency admission, although IMD quintile was not associated with conversion probabilities. The VPC of the fully adjusted model was 0.06 .

\section{Sensitivity analysis}

Including missing data category to gestational birth for all final adjusted models did not change the interpretation of the main findings (supplementary table S6).

\section{Discussion}

\section{Key results}

Rates of emergency department use were highest amongst infants born $<32$ weeks gestation, with presence of congenital anomaly and to mothers $<20$-years-old. Higher area-level deprivation was associated with higher A\&E attendance rates and emergency admission rates, but not associated with conversion probability (A\&E attendances resulting in admission). A\&E attendance rates highest in the North East and London, although London had the lowest emergency admission rates and conversion probability. There were some variations in A\&E attendance and emergency admission rates respectively by LA, that were not explained by infant or maternal characteristics.

\section{Strengths and limitations}

This was a large study including over 3 million infants, allowing us to account for multiple infant and maternal health related risk factors for A\&E attendances and admissions, including some which are uncommon (eg severe prematurity). The strengths of our study include the use of a nationally validated birth cohort generated using administrative HES data covering $97 \%$ of births in England, minimising selection bias and ensuring inclusion of vulnerable groups (eg children with congenital anomalies). Further linkage to HES A\&E and APC records ( $99 \%$ high standard of quality linkage, $85 \%$ as strong link, $15 \%$ as good link) enabled us to follow-up infants during the first year of their life and include individual-level information within the statistical modelling. However, $8 \%$ of A\&E-APC records did not link to a birth cohort record, of which $89 \%$ were from the A\&E dataset. Some of these records could have been of non-resident infants born outside of England (either on holiday or moved to England after birth), multiple births, and some may have been of infants with mothers that were asylum seekers/refugees without NHS numbers. The A\&E dataset has been subject to data quality issues which likely also contribute to non-links (2). Partly to address these data quality issues, NHS Digital have recently developed the new Emergency Care Data Set to replace the HES A\&E dataset; a full evaluation of the ECDS for child health research has yet to be carried out (44). Currently the ECDS data does not include a personidentifier, which prevents linkage of records longitudinally or to a birth cohort.

$14 \%$ of births in the cohort were excluded during analyses due to complete case analysis, which was mainly due to high proportion of missing data on infant gestational age. We therefore conducted sensitivity analysis including the missing gestational age to investigate any potential bias. The results were broadly similar, suggesting that our findings and conclusions are unlikely to be biased by missing data. Our birth cohort excluded multiple births to avoid increasing risks of false matches for multiple births $(27,45)$. Due to limited data in HES A\&E dataset on diagnoses, we did not investigate clinical condition severity for attendances and admissions.

\section{Comparison with other studies and implications for policy}

We found higher rates of A\&E attendances, emergency admissions and conversion probabilities amongst infants born severely premature, with congenital anomalies and young mothers (<20-years old). Similar findings on A\&E attendances and emergency admissions have been reported in other studies conducted in England $(5,12,46,47)$, but our study also add to the literature by investigating conversion from A\&E to hospital admissions, and demonstrates that the local area variation in A\&E attendances and

Page $11 / 19$ 
admission rates cannot be explained by infant level factors. However, infants from the most deprived SES quintile had $14 \%$ higher rates of $A \& E$ attendances compared to those from the least deprived. But of those that had an attendance, SES quintile were not associated with conversion probability. This suggests that it is likely to be the underlying severity of illness and risk profile that drives infant admissions, rather than area-level deprivation. Mothers from more deprived areas may not have alternative community or primary care support, so may end up in A\&E with their infants who do not require emergency admissions and could have been treated elsewhere. This maybe further influenced by the reduction in community based postnatal care provisions (i.e. in health care visiting and management of neonates in the community following birth discharge) $(13,14)$. Indeed, as conversion rates increased across the study period, this suggests an overall system failure. Thus, effective implementation of preventative healthcare from elsewhere in the community (healthcare visitors) and primary care could potentially reduce A\&E attendances for vulnerable infants, younger mothers, and parents of low SES. Research has suggested that access difficulties and dissatisfaction with primary care services, maybe resulting those from in lower SES backgrounds opting to attend hospital rather than in primary care (48-50). Recent qualitative research has shown young disadvantaged mothers have complex needs that are not currently addressed by the current systems of care (51).

Nevertheless, individual-level factors (maternal and infant factors) did not account for substantial variations in A\&E attendances and emergency admissions by geographical area. Adding LA random effect accounted for substantial variations in A\&E attendances and emergency admissions; highlighting differences introduced by unobserved factors at LA level. These factors could include (but are not limited to) local area level determinants such as healthcare policy, expenditure, supply constraints, distance from home to hospital (travel time for parents which would be longer in rural areas compared to urban areas), hospital level admission thresholds driven by local policies, and other socio-economic determinants not captured by our model (such as household income, parental education and occupation) $(52,53)$. Future research accounting for these factors would yield meaningful understanding of pathways leading to the continued increases in hospital contact. In-depth investigation into local areas performing particularly well or poorly on reducing emergency admissions given their underlying population characteristics would provide insights into cost-effective strategies for reducing need for hospital contacts for families with young infants.

We found rates of A\&E attendances and emergency admission for infants continue to increase each year with large regional variations across England; as previously reported $(2,3,7-12,15,16,54)$. London had high A\&E attendance rates $(876 / 1000)$, but the lowest emergency admission rates (232/1000) and conversion proportion (25\%). One explanation for this could be due to more Short-Stay Paediatric Assessment Units (SSPAUs; hospital-based facilities where infants with acute illness, injury or other urgent referrals can be assessed, observed and treated with an expectation of discharge in less than 24 hours) being co-located within emergency departments in London compared with the rest of the UK; $35 \%$ of SSPAUs in London, compared to approximately $21 \%$ across the UK (22). Further investigation of the route of admissions revealed a substantial proportion of emergency admissions were via direct admissions (primarily via GPs, 92\%), where parents did not attend A\&E. This was particularly the case outside of London. Further investigation of detailed LA level factors in future research should lead to better understanding of drivers of geographical variations.

During the first three months of the Covid-19 pandemic, children aged 0-4 years attended A\&E departments in England substantially less compared to the same period in 2019 (visits for illnesses 64\% lower and visits for injuries 35\% lower) (55). Concerns about parents delaying presentation to emergency departments for high-risk children lead to RCPCH guidelines and alterations in NHS-111 algorithms indicating when A\&E visit would be essential (identifying red-flag symptoms) (56-58). GP telephone and video consultations enabled parents with young children to access healthcare advice remotely (59). Continuing to improve remote primary care access for parents and tailored preventative guidance for high-risk infants (infants born preterm, with presence of congenital anomaly, and young parent families from low SES background) may help curb pressure on emergency departments.

\section{Conclusion}

Our findings have important implications for policy related to A\&E attendances and emergency admission among infants. The central aim of health policy in England and the NHS 10-year plan has been to reduce rates of emergency admissions by making improvement to other parts of the health care system. We found substantial geographical variations in emergency department

Page $12 / 19$ 
use, which were highest amongst vulnerable infants including those born severely preterm, with presence of congenital anomaly and with young mothers. The key policy implication is to continue improvements to out of hospital care (already implemented during pandemic in England) to provide effective ways of assisting parents to access appropriate support for infants in primary care and community-based settings (by GPs and healthcare visitors). We also found that LA random effect accounted for substantial variations in emergency department use, suggesting that heterogeneity within LAs results from unobserved factors at that level. As area-level deprivation were not associated with increasing conversion probability, that suggests overall system level failures are required to be addressed within services. Future research using more detailed LA level data and including underlying service-level factors, would provide insights into cost-effective strategies for reducing hospital contacts for families with young infants.

\section{Declarations}

\section{Ethics approval and consent to participate}

This work uses data provided by patients and collected by the NHS as part of their care and support. The use of Hospital Episodes Statistics data was approved by NHS Digital for the purpose of this study (DARS-NIC-393510-D6H1D-v6.11). Source data can be accessed by researchers applying to the data owner, NHS Digital. The views expressed in this publication are those of the author(s) and not necessarily those of the NHS, the National Institute for Health Research, the Department of Health and Social Care or its arm's length bodies, and other Government Departments

Informed consent from the patient was waived from the Ethics Committee, as the data used in this study were obtained from a national routine healthcare system established by the government. Data use was authorized by NHS Digital, and data provided to us were de-identified.

\section{Consent for publication}

Not applicable

\section{Availability of data and materials}

Source data can be accessed by researchers applying to the Health and Social Care Information Centre for England. Copyright () 2018. Reused with the permission of the Health and Social Care Information Centre.

\section{Competing interests}

The authors have declared that no competing interests exist.

\section{Funding}

This work, SN and KL are supported by the National Institute for Health Research (NIHR) School for Public Health Research (Grant Reference Number PD-SPH-2015). The NIHR School for Public Health Research is a partnership between The University of Sheffield; University of Bristol; University of Cambridge; Imperial College London and University College London; London School for Hygiene \& Tropical Medicine (LSHTM); LiLaC, a collaboration between the University of Liverpool and Lancaster University; and Fuse, The Centre for Translational Research in Public Health which is a collaboration between the Newcastle University, Durham University, Northumbria University, University of Sunderland and Teesside University. The views expressed are those of the authors and not necessarily those of the NIHR or the Department of Health and Social Care. Research at UCL Great Ormond Street Institute of Child Health is supported by the NIHR Great Ormond Street Hospital Biomedical Research Centre. This research benefits from and contributes to the NIHR Children and Families Policy Research Unit but was not commissioned by the NIHR Policy Research Programme.

\section{Authors' contributions}


All authors have contributed to the conducting of this study. SN, PH and RV planned and designed the study based on an initial idea and conception by PH. SN conducted statistical analysis with support from PH, AZ, \& KL. MCB provided guidance on statistical analysis and interpretation. SN prepared the first manuscript draft, and all authors provided substantial contribution to interpretation of the results and manuscript revisions. AZ, PH and LW obtained data and conducted initial work on generating mother-baby birth cohort. PH and RV obtained funding to conduct the study. All authors approved the final manuscript; and have read, and confirm that they meet, International Committee of Medical Journal Editors (ICMJE) criteria for authorship.

\section{Acknowledgements}

We would like to thank Prof David Cromwell and Rachel Pearson on providing guidance on generating funnel plots, which were adapted for the current study. This work uses data provided by patients and collected by the NHS as part of their care and support.

\section{References}

1. Kossarova L, Cheung R, Hargreaves D, Keeble E. Admissions of inequality: emergency hospital use for children and young people London: Nuffield Trust2017 [Available from: https://www.nuffieldtrust.org.uk/files/2017-12/nt-admissions-ofinequality-web.pdf.

2. Keeble E, Kossarova L. Focus on: Emergency hospital care for children and young people 2017 [Available from: http://allcatsrgrey.org.uk/wp/download/health_services/urgent_and_emergency_care_services/QualityWatch-CYP-report.pdf.

3. Keeble E, Fisher E. Briefing: Can variation help to explain the rise in emergency admissions for children aged under five up to 2018/19? 2020 [Available from: https://www.nuffieldtrust.org.uk/files/2021-01/under-5-s-summary-report-web.pdf.

4. Greenfield G, Blair M, Aylin PP, Saxena S, Majeed A, Hoffman M, et al. Frequent attendances at emergency departments in England. Emergency Medicine Journal. 2020;37(10):597-9.

5. Johnson L, Cornish R, Boyd A, Macleod JJBhsr. Socio-demographic patterns in hospital admissions and accident and emergency attendances among young people using linkage to NHS Hospital Episode Statistics: results from the Avon Longitudinal Study of Parents and Children. BMC health services research. 2019;19(1):134.

6. McHale P, Wood S, Hughes K, Bellis MA, Demnitz U, Wyke S. Who uses emergency departments inappropriately and when - a national cross-sectional study using a monitoring data system. BMC Medicine. 2013;11(1):258.

7. Jones E, Taylor B, Rudge G, MacArthur C, Jyothish D, Simkiss D, et al. Hospitalisation after birth of infants: cross sectional analysis of potentially avoidable admissions across England using hospital episode statistics. BMC pediatrics. 2018;18(1):390.

8. NHS Digital. Hospital Accident and Emergency Activity 2018-19 2019 [Available from: https://digital.nhs.uk/data-andinformation/publications/statistical/hospital-accident-emergency-activity/2018-19.

9. Gill PJ, Goldacre MJ, Mant D, Heneghan C, Thomson A, Seagroatt V, et al. Increase in emergency admissions to hospital for children aged under 15 in England, 1999-2010: national database analysis. Archives of disease in childhood. 2013;98(5):328-34.

10. Saxena S, Bottle A, Gilbert R, Sharland M. Increasing short-stay unplanned hospital admissions among children in England; Time Trends Analysis' 97-'06. PLoS One. 2009;4(10):e7484.

11. Sands R, Shanmugavadivel D, Stephenson T, Wood D. Medical problems presenting to paediatric emergency departments: 10 years on. Emerg Med J. 2012;29(5):379-82.

12. Harron K, Gilbert R, Cromwell D, Oddie S, Guttmann A, van der Meulen J. International comparison of emergency hospital use for infants: data linkage cohort study in Canada and England. BMJ Quality and Safety. 2018;27(1):31-9.

13. Care Quality Commission. 2018 Survey of Women's Experiences of Maternity Care: Statistical release 2019 [Available from: https://www.cqc.org.uk/sites/default/files/20190424_mat18_statisticalrelease.pdf.

14. Institute of Health Visiting. Health Visiting in England: A vision for the future. 2019 [Available from: https://ihv.org.uk/wpcontent/uploads/2019/11/7.11.19-Health-Visiting-in-England-Vision-FINAL-VERSION.pdf. 
15. Public Health England. Fingertips: Child health profiles: Healthcare use - A\&E attendances (under 1 year) 2020 [Available from: https://fingertips.phe.org.uk/profile/child-health-

profiles/data\#page/4/gid/1938133230/pat/15/par/E92000001/ati/6/are/E12000004/iid/92493/age/2/sex/4/cid/4/tbm/1.

16. Public Health England. Fingertips: Child health profiles: Healthcare use - Emergency admissions (rate per 1000 population) $<1$ 2020 [Available from: https://fingertips.phe.org.uk/profile/child-healthprofiles/data\#page/4/gid/1938133230/pat/15/par/E92000001/ati/6/are/E12000004/iid/92680/age/2/sex/4/cid/4.

17. Satokangas M, Arffman M, Antikainen H, Leyland AH, Keskimäki I. Individual and Area-level Factors Contributing to the Geographic Variation in Ambulatory Care Sensitive Conditions in Finland: A Register-based Study. Medical care. 2021;59(2):123.

18. Wallar LE, Rosella LC. Individual and neighbourhood socioeconomic status increase risk of avoidable hospitalizations among Canadian adults: A retrospective cohort study of linked population health data. International Journal of Population Data Science. 2020;5(1).

19. Lemer C. Annual report of the Chief Medical Officer 2012: our children deserve better: prevention pays. 2013.

20. NHS England. The NHS Long Term Plan 2019 [Available from: https://www.longtermplan.nhs.uk/wpcontent/uploads/2019/01/nhs-long-term-plan-june-2019.pdf.

21. Clinical Indicators Team NHS Digital. NHS Outcomes Framewok: Quarterly Publiation 2019 [Available from: https://digital.nhs.uk/data-and-information/publications/clinical-indicators/nhs-outcomes-framework.

22. Royal College of Paediatrics and Child Health (RCPCH). Standards for Short-Stay Paediatric Assessment Units (SSPAU) 2017 [Available from: https://www.rcpch.ac.uk/sites/default/files/SSPAU_College_Standards_21.03.2017_final.pdf.

23. Royal College of Paediatrics and Child Health (RCPCH). Facing the Future: Together for Child Health 2015 [Available from: https://www.rcpch.ac.uk/sites/default/files/Facing_the_Future_Together_for_Child_Health.pdf.

24. Coon JT, Martin A, Abdul-Rahman A-K, Boddy K, Whear R, Collinson A, et al. Interventions to reduce acute paediatric hospital admissions: a systematic review. Archives of disease in childhood. 2012;97(4):304-11.

25. Herbert A, Wijlaars L, Zylbersztejn A, Cromwell D, Hardelid P. Data resource profile: hospital episode statistics admitted patient care (HES APC). International journal of epidemiology. 2017;46(4):1093-i.

26. Boyd A, Cornish R, Johnson L, Simmonds S, Syddall H, Westbury L, et al. Understanding Hospital Episode Statistics (HES). Bristol, UK: University of Bristol; 2018.

27. Harron K, Gilbert R, Cromwell D, van der Meulen J. Linking data for mothers and babies in de-identified electronic health data. PLoS One. 2016;11(10):e0164667.

28. Zylbersztejn A, Gilbert R, Hjern A, Wijlaars L, Hardelid P. Child mortality in England compared with Sweden: a birth cohort study. The Lancet. 2018;391(10134):2008-18.

29. NHS Digital. HES Accident \& Emergency (A\&E) to Admitted Patient Care (APC) Linkage Methodology 2011 [Available from: http://www.macs.hw.ac.uk/ yjc32/project/ref-health\%20hospital\%20data/AE_to_APC_Linkage_Methodology1.pdf.

30. NHS Digital. Hospital Episode Statistics (HES) Analysis Guide 2019 [Available from: https://digital.nhs.uk/data-andinformation/data-tools-and-services/data-services/hospital-episode-statistics/users-uses-and-access-to-hospital-episodestatistics.

31. Goldenberg RL, Culhane JF, lams JD, Romero R. Epidemiology and causes of preterm birth. The lancet. 2008;371(9606):7584.

32. Hardelid P, Dattani N, Davey J, Pribramska I, Gilbert R. Overview of child deaths in the four UK countries. Child Health Reviews-UK. London: Royal College of Paediatrics and Child Health; 2013.

33. Penman-Aguilar A, Carter M, Snead MC, Kourtis AP. Socioeconomic disadvantage as a social determinant of teen childbearing in the US. Public Health Reports. 2013;128(2_suppl1):5-22.

34. Department for Communities and Local Government. English Indices of Deprivation 2010 [Available from: https://assets.publishing.service.gov.uk/government/uploads/system/uploads/attachment_data/file/6871/1871208.pdf.

35. Ministry for Communities \& Local Government. English indices of deprivation 2020 [Available from: https://www.gov.uk/government/collections/english-indices-of-deprivation. 
36. NHS Digital. Hospital Admitted Patient Care Activity 2019-20 2020 [Available from: https://digital.nhs.uk/data-andinformation/publications/statistical/hospital-admitted-patient-care-activity/2019-20.

37. Cleves M, Gould W, Gutierrez RG, Marchenko Y. An Introduction to Survival Analysis Using Stata (Revised 3rd Edition). StataCorp LP; 2016. Report No.: 1597180742.

38. Leckie G, Browne W, Goldstein H, Merlo J, Austin P. Variance partitioning in multilevel models for count data. arXiv preprint arXiv:191106888. 2020.

39. Austin PC, Stryhn H, Leckie G, Merlo J. Measures of clustering and heterogeneity in multilevel Poisson regression analyses of rates/count data. Statistics in medicine. 2018;37(4):572-89.

40. Kuha J. AIC and BIC: Comparisons of assumptions and performance. Sociological methods \& research. 2004;33(2):188-229.

41. Spiegelhalter DJ. Funnel plots for comparing institutional performance. Statistics in medicine. 2005;24(8):1185-202.

42. Goldstein H, Browne W, Rasbash J. Partitioning variation in multilevel models. Understanding statistics: statistical issues in psychology, education, and the social sciences. 2002;1(4):223-31.

43. StataCorp. Stata Statistical Software: Release 15. 2017.

44. NHS Digital. Emergency Care Data Set (ECDS) 2021 [Available from: https://digital.nhs.uk/data-and-information/datacollections-and-data-sets/data-sets/emergency-care-data-set-ecds.

45. Zylbersztejn A, Gilbert R, Hardelid P. Developing a national birth cohort for child health research using a hospital admissions database in England: The impact of changes to data collection practices. PloS one. 2020;15(12):e0243843.

46. Coathup DD, Boyle E, Carson C, Johnson S, Kurinzcuk J, Macfarlane A, et al. Gestational age and hospital admissions during childhood, the TIGAR study: a population-based, record linkage study in England. BMJ. 2020;2020(055130):R1.

47. Hardelid P, Verfuerden M, McMenamin J, Smyth RL, Gilbert R. The contribution of child, family and health service factors to respiratory syncytial virus (RSV) hospital admissions in the first 3 years of life: birth cohort study in Scotland, 2009 to 2015. Eurosurveillance. 2019;24(1):1800046.

48. Agarwal S, Banerjee J, Baker R, Conroy S, Hsu R, Rashid A, et al. Potentially avoidable emergency department attendance: interview study of patients' reasons for attendance. Emergency Medicine Journal. 2012;29(12):e3-e.

49. MacKichan F, Brangan E, Wye L, Checkland K, Lasserson D, Huntley A, et al. Why do patients seek primary medical care in emergency departments? An ethnographic exploration of access to general practice. BMJ Open. 2017;7(4):e013816.

50. Kangovi S, Barg FK, Carter T, Long JA, Shannon R, Grande D. Understanding why patients of low socioeconomic status prefer hospitals over ambulatory care. Health affairs. 2013;32(7):1196-203.

51. Buchanan S, Jardine C. The complex information needs of disadvantaged young first-time mothers: insights into multiplicity of needs. Journal of Documentation. 2020;76(6):1135-53.

52. Castro A, Doran T, Bloor K, Shaw R, Cookson R. Local NHS equity trends and their wider determinants: A pilot study of data on emergency admissions 2020 [Available from:

https://www.york.ac.uk/media/healthsciences/documents/research/Local_NHS_Equity_Trends.pdf.

53. Busby J, Hollingworth W, Purdy S. The role of general practice in reducing unplanned hospital admissions. British Journal of Hospital Medicine. 2017;78(4):186-7.

54. Lewis KM, De Stavola B, Hardelid P. Is socioeconomic position associated with bronchiolitis seasonality? A cohort study. Journal of Epidemiology \& Community Health. 2021;75(1):76-83.

55. McConkey R, Hargreaves D, Wyatt S. How has children and young people's usage of A\&E been impacted by lockdown and social distancing? 2020 [Available from: https://www.health.org.uk/news-and-comment/charts-and-infographics/how-haschildren-and-young-peoples-usage-of-AE-been-impacted-by-lockdown-and-social-distancing.

56. Roland D, Harwood R, Bishop N, Hargreaves D, Patel S, Sinha I. Children's emergency presentations during the COVID-19 pandemic. The Lancet Child \& Adolescent Health. 2020;4(8):e32-e3.

57. Royal College of Paediatrics and Child Health (RCPCH). Advice for parents during coronavirus 2020 [Available from: https://www.rcpch.ac.uk/sites/default/files/2020-04/covid19_advice_for_parents_when_child_unwell_or_injured_poster.pdf. 
58. Royal College of Paediatrics and Child Health (RCPCH). COVID-19 - resources for parents and carers 2021 [07/05/2021]. Available from: https://www.rcpch.ac.uk/resources/covid-19-resources-parents-carers.

59. Car J, Koh GC-H, Foong PS, Wang CJ. Video consultations in primary and specialist care during the covid-19 pandemic and beyond. bmj. 2020;371.

\section{Figures}

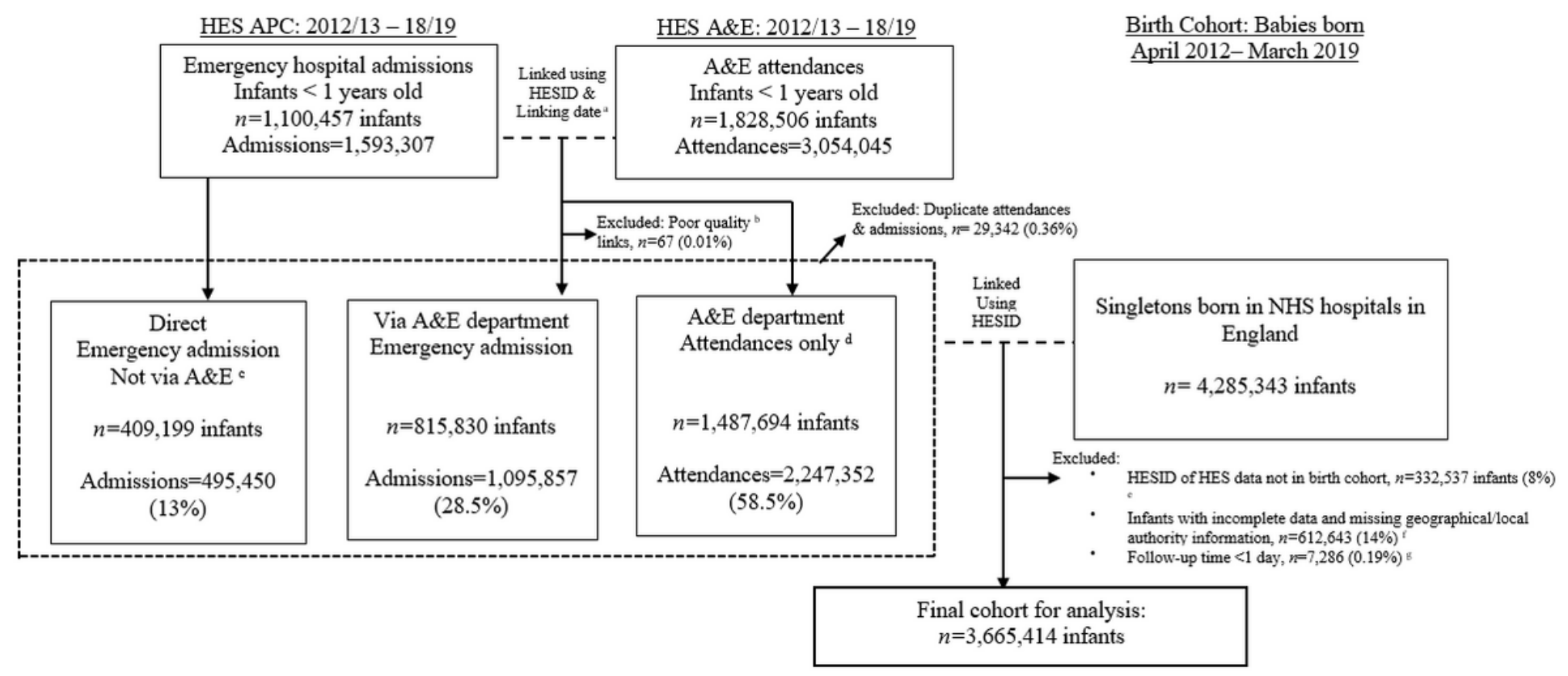

Figure 1

Flow chart of linkage between HES APC, HES A\&E and birth cohort data

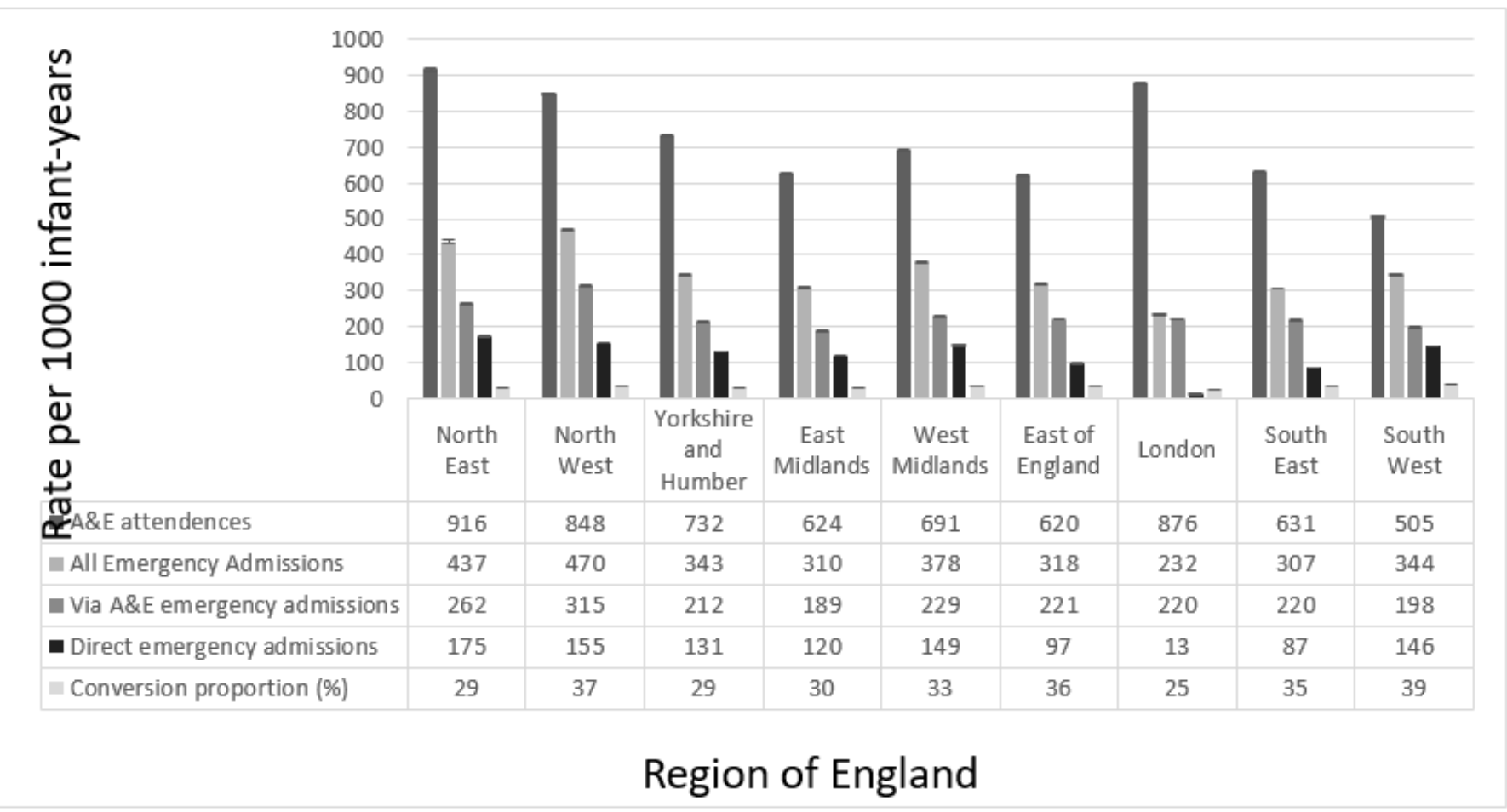

Figure 2 
A\&E attendances and emergency admissions for infants $<1$ years old in England by Region of residence

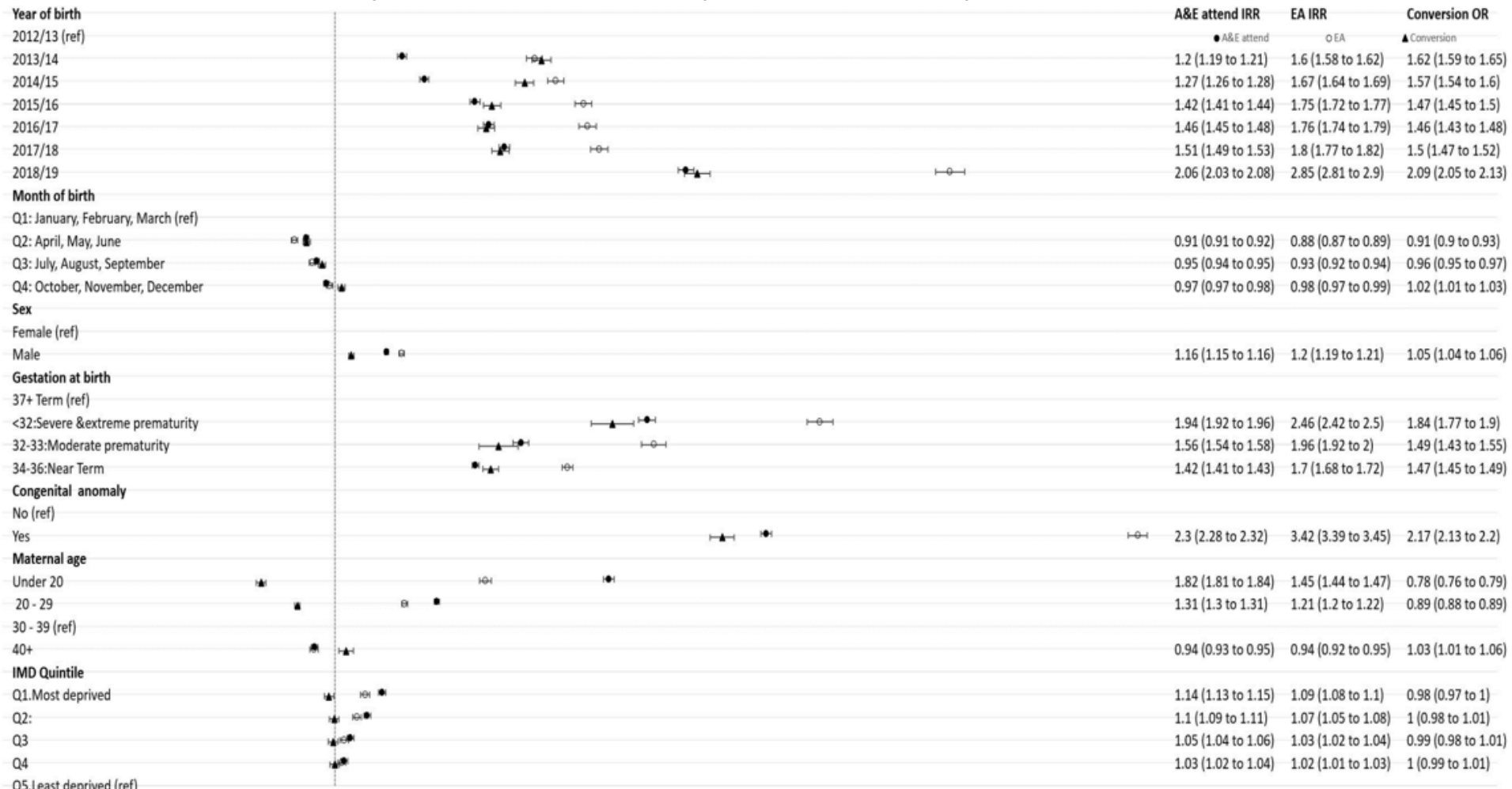

Q5.Least deprived (ref)

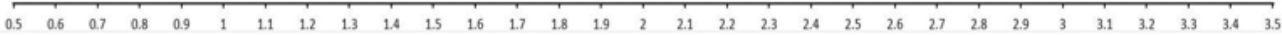

\section{Figure 3}

Adjusted IRRs for A\&E attendences, Emergency Admissions (EA) and ORs for conversion (including 95\% Cl) Acronyms: IRR Incidence Rate Ratio; OR - Odds Ratio; $\mathrm{Cl}$ - Confidence Interval

A: Map of A\&E attendance rates

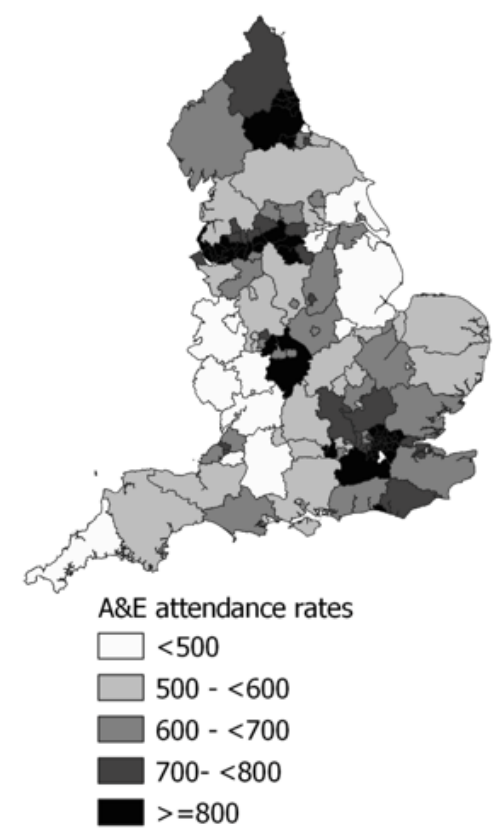

B: Map of emergency admission rates

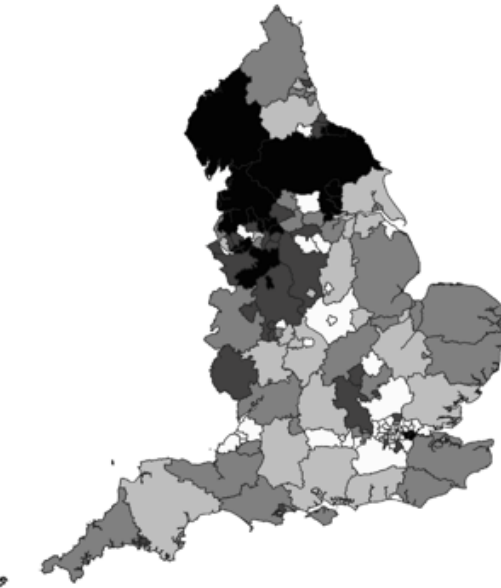

Emergency admission rates

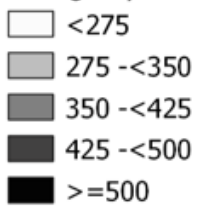

C: Map of conversion probabilities

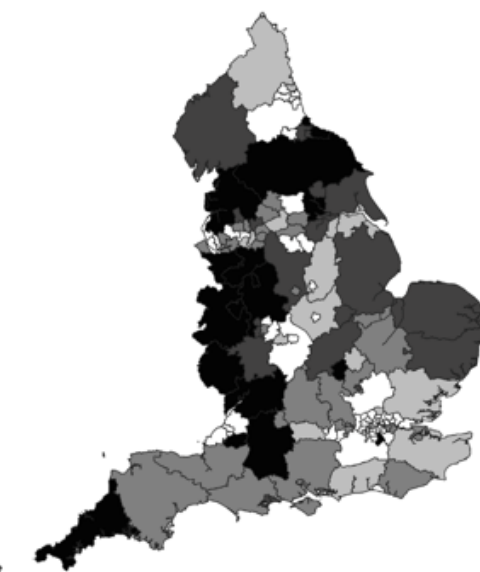

Conversion probabilities

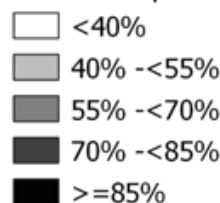

Figure 4 
Maps showing adjusted rates (per 1000 child-years) of A\&E attendences (A), emergency admissions (B) and converstion probabilities (C) by local authorities in England between finacial years 2013/14 - 2018/19

A: Funnel plot of A\&E attendance rates for infants by local authority

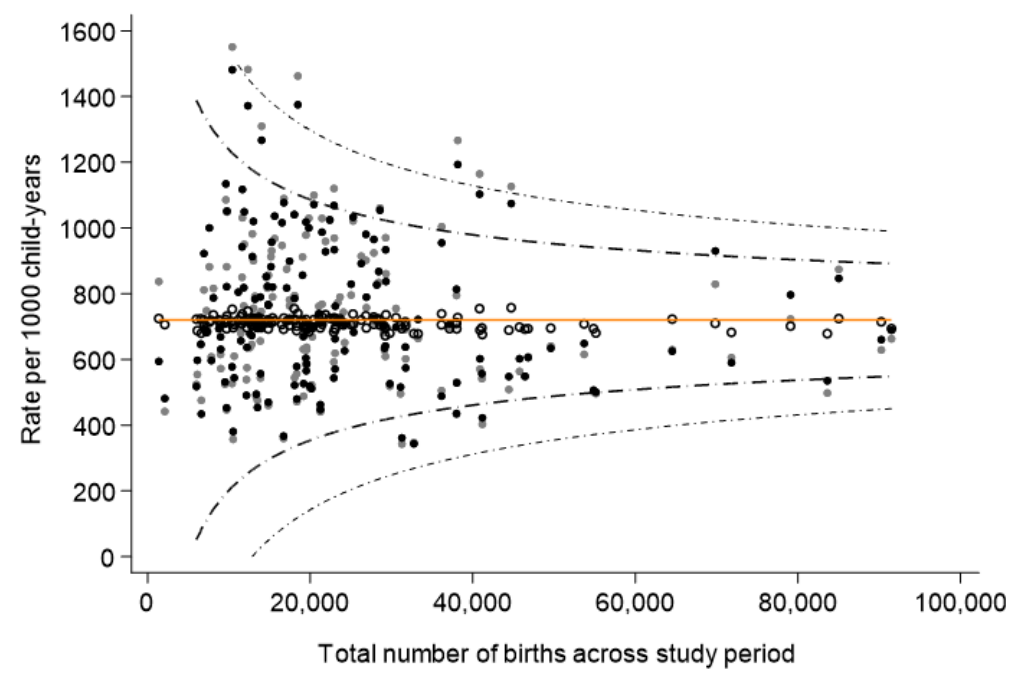

B: Funnel plot of emergency admission rates for infants by local authority

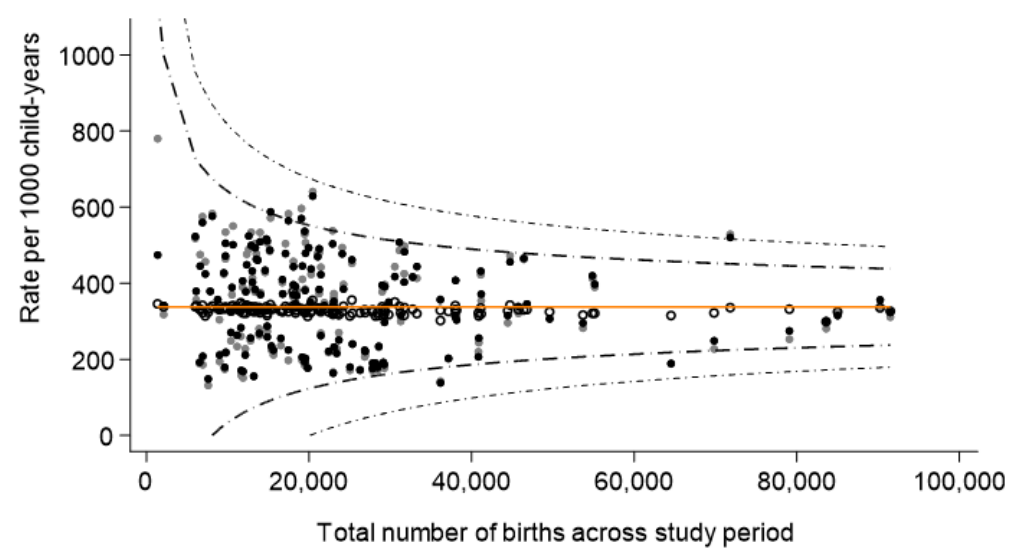

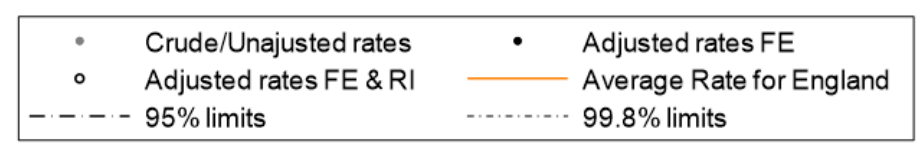

\section{Figure 5}

Funnel plots of unadjusted and adjusted $A \& E$ attendance $(A)$ and emergency admission (B) rates by local authorities in England between financial years 2013/14 - 2018/19. FE - Fixed effects, RI - Random Intercept

\section{Supplementary Files}

This is a list of supplementary files associated with this preprint. Click to download.

- OnlineSupplementaryInformationBMCHSR.docx 